\title{
Gap-junction channels inhibit transverse propagation in cardiac
} muscle

\author{
Nicholas Sperelakis*1 and Lakshminarayanan Ramasamy²
}

Address: ${ }^{1}$ Dept. of Molecular \& Cellular Physiology, University of Cincinnati College of Medicine, Cincinnati, OH 45267-0576, USA and ${ }^{2}$ Dept. of Electrical Computer Engineering and Computer Science, University of Cincinnati, College of Engineering Cincinnati, OH 45221, USA

Email: Nicholas Sperelakis* - spereln@ucmail.uc.edu; Lakshminarayanan Ramasamy - laksnarayana@yahoo.com

* Corresponding author

Published: 28 January 2005

BioMedical Engineering OnLine 2005, 4:7 doi:10.1 186//475-925X-4-7
Received: 12 October 2004

Accepted: 28 January 2005

This article is available from: http://www.biomedical-engineering-online.com/content/4/I/7

(C) 2005 Sperelakis and Ramasamy; licensee BioMed Central Ltd.

This is an Open Access article distributed under the terms of the Creative Commons Attribution License (http://creativecommons.org/licenses/by/2.0), which permits unrestricted use, distribution, and reproduction in any medium, provided the original work is properly cited.

\begin{abstract}
The effect of adding many gap-junctions $(\mathrm{g}-\mathrm{j})$ channels between contiguous cells in a linear chain on transverse propagation between parallel chains was examined in a $5 \times 5$ model $(5$ parallel chains of 5 cells each) for cardiac muscle. The action potential upstrokes were simulated using the PSpice program for circuit analysis. Either a single cell was stimulated (cell $\mathrm{Al}$ ) or the entire chain was stimulated simultaneously (A-chain). Transverse velocity was calculated from the total propagation time (TPT) from when the first AP crossed a $V_{m}$ of $-20 \mathrm{mV}$ and the last AP crossed $-20 \mathrm{mV}$. The number of g-j channels per junction was varied from zero to $100,1,000$ and $10,000\left(R_{g j}\right.$ of $\infty, 100$ $\mathrm{M} \Omega$, $10 \mathrm{M} \Omega$, I.0 $\mathrm{M} \Omega$, respectively). The longitudinal resistance of the interstitial fluid (ISF) space between the parallel chains $\left(R_{\mathrm{OI} 2}\right)$ was varied between $200 \mathrm{~K} \Omega$ (standard value) and I.0, 5.0, and I0 $M \Omega$. The higher the $R_{\mathrm{o} 12}$ value, the tighter the packing of the chains. It was found that adding many g-j channels inhibited transverse propagation by blocking activation of all 5 chains, unless $R_{\mathrm{ol} 2}$ was greatly increased above the standard value of $200 \mathrm{~K} \Omega$. This was true for either method of stimulation. This was explained by, when there is strong longitudinal coupling between all 5 cells of a chain awaiting excitation, there must be more transfer energy (i.e., more current) to simultaneously excite all 5 cells of a chain.
\end{abstract}

\section{Introduction}

We have developed an electric field hypothesis for the mechanism of transmission of excitation from one cell to the next that does not require gap-junction channels [1-4]. In the electric field hypothesis, the electrical voltage that develops in the narrow junctional cleft $\left(\mathrm{V}_{\mathrm{jc}}\right)$ when the prejunctional membrane generates an action potential, serves to depolarize the postjunctional membrane its threshold, by a patch-clamp-like effect. The parameters that affect the magnitude of Vjc include the size of $\mathrm{R}_{\mathrm{j}{ }^{\prime}}$ the transverse resistance of the junctional cleft. This results in excitation of the postjunctional cell, after a brief junctional delay. The total propagation time consists primarily of the summed junctional delays. This results in a staircase-shaped propagation, the surface sarcolemma of each cell firing almost simultaneously [2].

There are no low-resistance connections between the cells in several different cardiac muscle and smooth muscle preparations (reviewed in $[3,4]$. Propagation by 
mechanisms not requiring low-resistance connections have also been proposed by others [5-8]. Propagation has been demonstrated to be discontinuous (or saltatory) in cardiac muscle [9-12]. Fast $\mathrm{Na}^{+}$channels are localized in the junctional membranes of the intercalated discs of cardiac muscle [13-15] Sperelakis, 1995, a requirement for the EF mechanism to work $[3,4,1,2,13]$. In connexin-43 and $\mathrm{Cx} 40$ knockout mice, propagation in the heart still occurs, but it is slowed [15-19], as predicted by our PSpice simulation study [20]. It was reported that the anisotropic conduction velocity observed in the heart is not a result of cell geometry [21].

Subsequently, we published a series of papers on the longitudinal and transverse propagation of action potentials in cardiac muscle and smooth muscle using PSpice analysis $[22,20,23,24]$. In the review process for our recent paper [24], one of the referees asked us to determine the effect of introducing strong cell coupling via gap-junction (g-j) channels between cells within each chain on the transverse propagation in our $5 \times 5$ model $(5$ parallel chains of 5 cells each). Unexpectedly, we found that strong cell coupling $(10,000$ or 1,000 g-j channels per junction) actually inhibited transverse propagation. This fact was briefly mentioned as an unpublished observation in that paper. The purpose of the present study was to do a thorough investigation of that strange phenomenon. The results showed that, in cardiac muscle, transverse propagation was inhibited when many g-j channels were added between cells of each chain. This was true when either a single cell in the first chain was stimulated (cell A1) or the entire chain (A-chain) was stimulated simultaneously.

\section{Methods}

Details of the methods used and modeling of the PSpice analysis were given in our previous papers, including the limitations [21-24]. The full version of the PSpice software for circuit analysis/design was obtained from the Cadence Co. (Portland, OR). The assumptions made were given previously, including the entire circuit that was used [22]. An abbreviated version of the circuitry is given in the first two figures. The surface membrane of each myocardial cell was represented by 2 units and each junctional membrane by 1 unit (Figs. 1,2). The values for the circuit parameters used under standard conditions were given previously for both the surface units and junctional units in cardiac muscle [22]. The myocardial cell was assumed to be a cylinder $150 \mu \mathrm{m}$ long and $16 \mu \mathrm{m}$ in diameter. The myocardial cell capacitance was assumed to be $100 \mathrm{pF}$, and the input resistance to be $20 \mathrm{M} \Omega$. A junctional tortuosity (interdigitation) factor of 4 was assumed for the cell junction.
The circuit used for each unit was kept as simple as possible, using only those ion channels that set the resting potential (RP) and predominate during the rising phase of the AP. We wanted to only inscribe the rising phase of the APs to study propagation in the 2-dimensional sheet of myocardial cells. It was not possible to insert a second or third "black-box" into the basic excitable units, because the system became erratic, therefore the dynamic behavior of the cardiac cell membrane was an approximation. The $\mathrm{RP}$ was $-80 \mathrm{mV}$, and the overshoot potential was $+30 \mathrm{mV}$ (AP amplitude of $110 \mathrm{mV}$ ). Propagation velocity was calculated from the measured total propagation time (TPT) (measured as the difference between when the APs of the first cell and last cell crossed $-20 \mathrm{mV}$ ) and cell length.

Because the PSpice program does not have a V-dependent resistance to represent the increase in conductance for $\mathrm{Na}^{+}$ ions in myocardial cells during depolarization and excitation, this function had to be simulated by a V-controlled current source (our "black-box") in each of the basic circuit units (Fig. 2). The current outputs of the black-box, at various membrane voltages, were calculated assuming a sigmoidal relationship between membrane voltage and resistance between $-60 \mathrm{mV}$ and $-30 \mathrm{mV}$. The $\mathrm{V}$ values used in the GTABLE were those recorded directly across the membrane. The excitabilities of the basic units were the same as in our previous papers [21-24].

The upper chain of cells was assumed to be bathed in a large volume of Ringer solution connected to ground. The external resistance $\left(R_{\mathrm{o}}\right)$ of this fluid was divided into two components: a radial (or transverse) resistance $\left(\mathrm{R}_{\mathrm{or}}\right)$ and a longitudinal resistance $\left(\mathrm{R}_{\mathrm{ol}}\right)$. The longitudinal resistance values $\left(\mathrm{R}_{\mathrm{ol} 2}\right)$ between the upper chain and interior chains were increased over a wide range to reflect packing of parallel chains into a bundle of fibers, with different degrees of tightness of the packing (Fig. 1). The higher the $\mathrm{R}_{\mathrm{ol} 2}$ value, the tighter the packing of the chains, i.e., the lower the cross-sectional area of the ISF space. The applicable equation is $\mathrm{R}_{\mathrm{ol} 2}=\rho(\Omega-\mathrm{cm}) \times \mathrm{L}(\mathrm{cm}) / \mathrm{Ax}\left(\mathrm{cm}^{2}\right)$, where $\rho$ is the resistivity of the ISF, $\mathrm{L}$ is the length, and $\mathrm{A}_{\mathrm{x}}$ is the crosssectional area of the ISF space. The transverse resistance of the interstitial fluid (ISF) space $\left(\mathrm{R}_{\mathrm{or} 2}\right)$ also reflects the closeness between the chains; the lower the $\mathrm{R}_{\mathrm{or} 2}$ value, the closer the chains are packed. In the present $5 \times 5$ model, there were five parallel chains (chains A, B, C, D, and E) of five cells each (cells 1-5). Electrical stimulation (rectangular current pulses of $0.25 \mathrm{nA}$ and $0.50 \mathrm{~ms}$ duration) was applied to the inside of either the first cell of chain A (cell A1) or all 5 cells of the A-chain. Under initial conditions, the cells in each chain were not interconnected by lowresistance pathways (gap junction channels), so that transmission of excitation from one cell to the next had to be by the EF developed in the narrow junctional cleft. Then gj-channels were added $(100,1,000$ and 10,000 


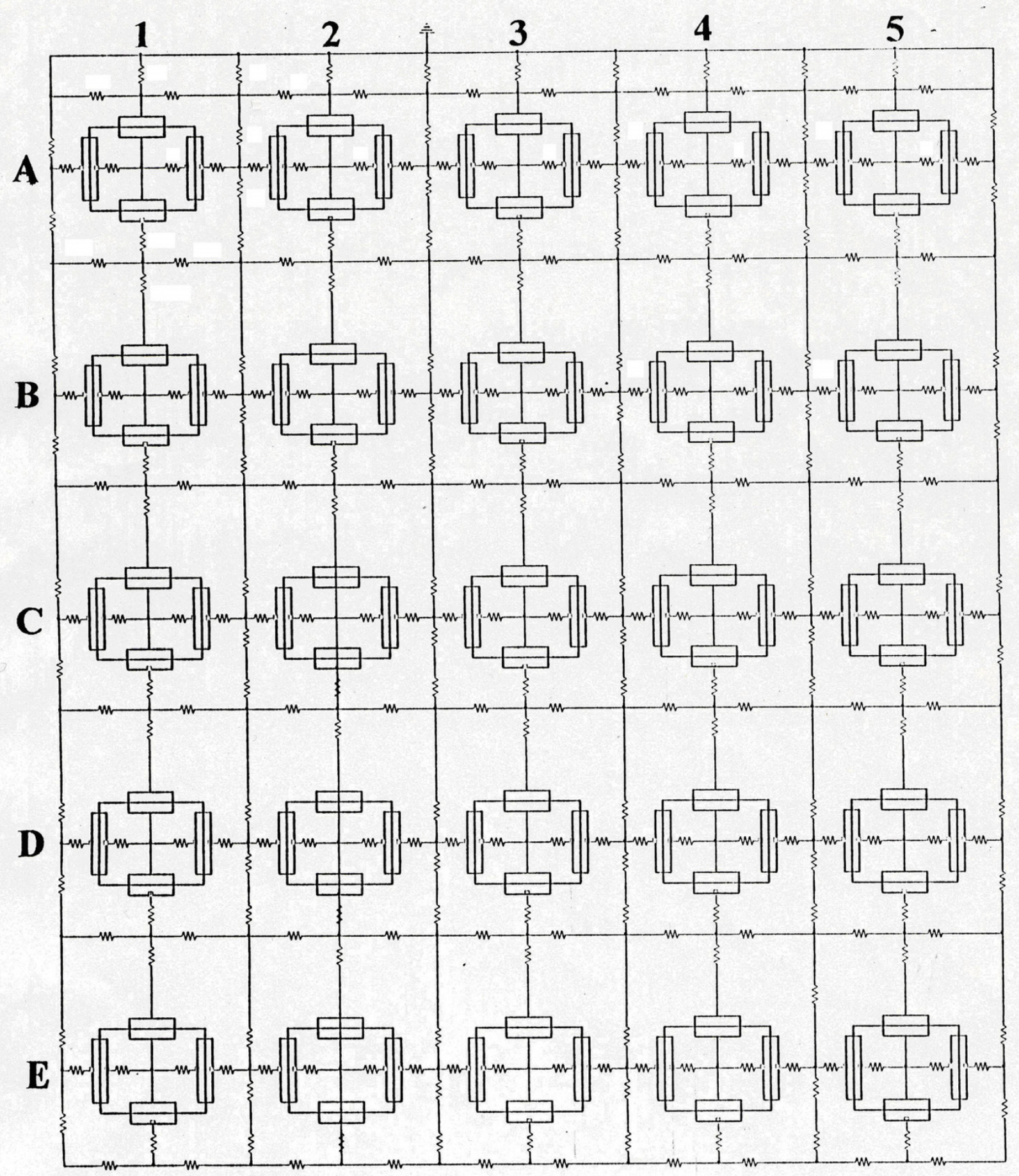

Figure I

The $5 \times 5$ model for cardiac muscle, consisting of 5 parallel strands (A-E) of 5 cells each (I-5) (total of 25 cells). Each muscle cell was represented by a block of 4 basic units: 2 units representing the surface membrane (one upward-facing and one downward-facing) and one unit for each of the two junctional membranes. For simplicity, the lumped resistance of the gap-junctions is not indicated here, but is shown in Fig. 2. Transverse propagation is sequential activation of chains $A$ to $B$ to $C$ to $D$ to $E$. 


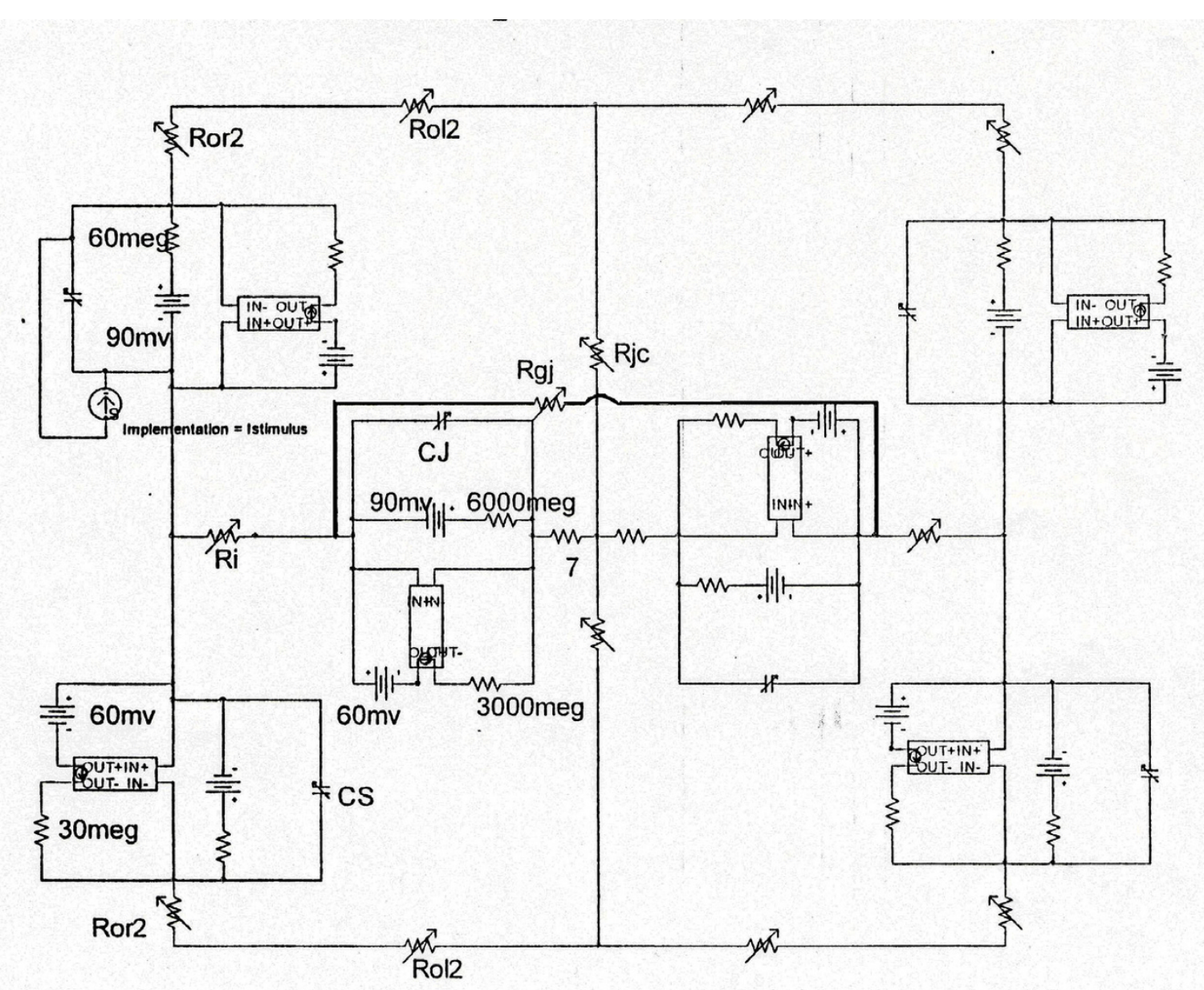

Figure 2

Blow-up of a small portion of the $5 \times 5$ model to show the electrical circuit for each basic unit, including the "black-box" required for excitability. $R_{\mathrm{o} 12}$ represents the longitudinal resistance of the interstitial fluid between the parallel chains; the higher the resistance, the tighter the packing of the chains. Depolarizing current $(0.25 \mathrm{nA})$ is applied to the interior of either the first cell or the entire chain (A-chain) simultaneously. When gap-junction channels were added, a resistor $\left(R_{g}\right)$ was inserted across each cell junction, from the interior of one cell to the interior of the next one.

channels per junction) to determine what effect they would have on transverse propagation. Since the number of functional gj-channels per junction have been estimated to be about a 1000 [12], we varied the number over a very wide range. The resistances of the gap-junction channels were lumped into one equivalent resistances because they are all in parallel.
As shown in Figure 1, there were two surface membrane units in each cell (one facing upwards and one inverted) and one unit for each of the junctional membranes (intercalated disks of cardiac muscle). To improve clarity, in some runs the $\mathrm{V}$-recording markers were placed on only one chain at a time. When all cells in a model were being recorded simultaneously (25 cells), the $\mathrm{V}$ markers were 
removed from most of the basic units to minimize confusion. That is, the voltage was recorded from only one surface unit (upward-facing) in each cell. The junctional cleft potential $\left(\mathrm{V}_{\mathrm{jc}}\right)$ was recorded across $\mathrm{R}_{\mathrm{ic}}$ the radial (or transverse) resistance of the narrow and tortuous junctional cleft. Under standard conditions, $\mathrm{R}_{\mathrm{ol} 2}$ was $200 \mathrm{~K} \Omega, \mathrm{R}_{\mathrm{or} 2}$ was $100 \Omega$, and $\mathrm{R}_{\mathrm{ic}}$ and was $25 \mathrm{M} \Omega(50 \mathrm{M} \Omega \div 2)$.

\section{Results}

The $5 \times 5$ model ( 5 parallel chains of 5 cells each) of cardiac muscle was used to examine whether addition of gapjunction (gj) channels between the cells in each chain would affect transverse propagation of simulated (PSpice) action potentials. The number of gj-channels was increased from zero (standard conditions; resistance of the gap junction $\left(\mathrm{R}_{\mathrm{gj}}\right)$ of infinite) to $100\left(\mathrm{R}_{\mathrm{gi}}=100 \mathrm{M} \Omega\right)$, $1000\left(\mathrm{R}_{\mathrm{gi}}=10 \mathrm{M} \Omega\right)$, and 10,000 $\left(\mathrm{R}_{\mathrm{gi}}=1.0 \mathrm{M} \Omega\right)$. Experiments were done with electrical stimulation $(0.5 \mathrm{nA}, 0.5$ $\mathrm{ms}$ ) of only the first cell of the first chain (A; cell A1) and with simultaneous stimulation of all 5 cells of the AChain (each cell receiving $0.5 \mathrm{nA}$ current). This second method of stimulation was done to obtain a more accurate assessment of strictly transverse propagation.

Figure 3 illustrates some of the results with stimulation of only cell A1. Panel A shows the standard conditions: $\mathrm{R}_{\mathrm{gj}}=$ $\infty$ (0 gj-channels) and $\mathrm{R}_{\mathrm{ol} 2}$ of $200 \mathrm{~K} \Omega$ (the longitudinal resistance of the interstitial space between the chains). As shown, all 5 chains ( 25 cells) responded. The total propagation time (TPT) was $4.2 \mathrm{~ms}$ (measured as the elapsed time between when the first and last APs crossed $-20 \mathrm{mV}$ ). When $10,000 \mathrm{~g}$-j channels were inserted into the cells of each chain $\left(R_{g j}=1.0 \mathrm{M} \Omega\right)$, then the last 2 chains ( $D$ and E) failed to respond (panel $B$ ). The 5 cells of each chain (A, B, and C) that responded now fired simultaneously because of the high degree of cell coupling, thereby giving only three AP traces, as shown. However, raising $\mathrm{R}_{\mathrm{ol} 2}$ to 10 $\mathrm{M} \Omega$ allowed all 5 chains to respond (Panel C), and propagation velocity was increased. These data are summarized in Table 1, part $\mathrm{A}$. Hence greatly elevating $\mathrm{R}_{\mathrm{Ol} 2}$ could overcome the impaired transverse propagation caused by the gj-channels.

Figure 4 illustrates some of the results with simultaneous stimulation of all 5 cells of the A-chain. Panel A shows the standard conditions: $\mathrm{R}_{\mathrm{gi}}=\infty$ and $\mathrm{R}_{\mathrm{ol} 2}=200 \mathrm{~K} \Omega$. As shown, all 5 chains responded (TPT was $3.6 \mathrm{~ms}$ ). Note that all 5 cells of the B - E chains did not respond simultaneously. When 10,000 gj-channels were added to the contiguous cells of each chain $\left(R_{g j}=1.0 \mathrm{M} \Omega\right)$, then the last 3 chains (C, D, and E) failed to respond (Panel B). The 5 cells of each chain that responded (A, B) now fired simultaneously because of the strong coupling. However, elevating $\mathrm{R}_{\mathrm{ol} 2}$ to $10 \mathrm{M} \Omega$ allowed all 5 chains to respond (Panel C). These data are summarized in Table 1, part B.
Figure 5 is a graphic summary of the results for both stimulation of only one cell (A1) (Panel A) and stimulation of the entire A-chain (Panel $\mathrm{B}$ ). The data include $\mathrm{R}_{\mathrm{gj}}$ values and $\mathrm{R}_{\mathrm{ol} 2}$ values not illustrated in Figures 3 and 4. As such, this figure is complementary to Table 1, but Table 1 lists the TPT values as well. As shown, progressive addition of gj- channels reduces the number of chains that respond, with both ways of stimulation, and progressive elevation of $\mathrm{R}_{\mathrm{ol} 2}$ reverses this inhibition.

\section{Discussion}

The results demonstrated that, in a cardiac muscle model, the insertion of many gj- channels, between abutting cells in each longitudinal chain of cells, actually inhibited transverse propagation of excitation between the parallel chains. This was true both for stimulation of only a single cell of the first chain (A-chain; cell A1) and for stimulation simultaneously of the entire 5 cells of the A-chain. The inhibition produced by the gj-channels could be overcome by greatly increasing the value of $\mathrm{R}_{\mathrm{ol} 2}$ (the longitudinal resistance of the narrow interstitial space between the parallel chains), reflecting tighter packing of the chains.

This finding surprised us at first. We were expecting either that there would be no effect on transverse transmission of excitation or that transverse transfer of excitation would be enhanced. But on further refection, the inhibition produced might be predicted. This is based on the fact that, with strong longitudinal coupling between cells, the entire chain of 5 cells must be simultaneously stimulated to threshold. Therefore, if the transverse transfer energy available is limited and is near threshold for a give chain, it is likely that some chains will fail to fire. Thus, the problem of strong coupling is not in the chains that are already excited, but rather in the quiescent adjacent chain which is in process of trying to become excited (D-chain in case of Fig. 3 and C-chain in Fig. 4). Strong coupling in the "inprocess" chain requires more energy transfer from the "already-activated" chain. If the "in-process" chain were not coupled by gi-channels, then if only one cell of the chain received enough stimulating energy to become activated, excitation would spread from it to the remaining cells of that chain. This idea was tested, and the results shown in Figure 6 are consistent with the mechanism proposed above. In panel $\mathbf{A}$, in which $\mathrm{R}_{\mathrm{gj}}$ was $1.0 \mathrm{M} \Omega(10,000$ gi-channels) uniformly in all 5 chains, chains $\mathrm{D}$ and $\mathrm{E}$ failed to fire. When $\mathrm{R}_{\mathrm{gj}}$ of just chains $\mathrm{D}$ and $\mathrm{E}$ were changed to infinity ( 0 channels), then all 5 chains fired (panel B). Therefore, the inhibition of transverse propagation can be reversed by uncoupling the cells of the chains that failed.

Consistent with the argument presented in the paragraph above, the transverse propagation velocity was not 

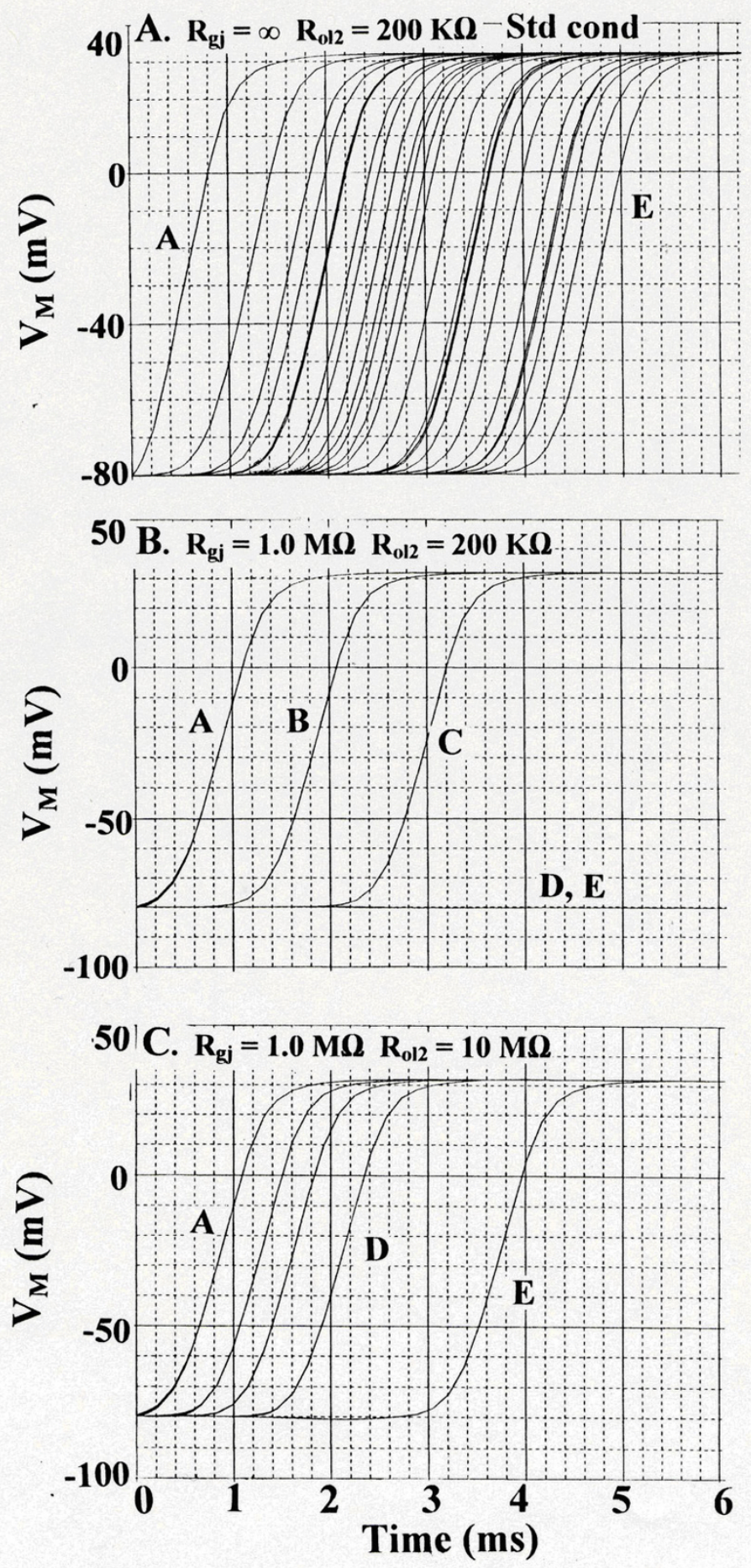

\section{Figure 3}

Transverse propagation of simulated action potentials (APs; rising phase) for cardiac muscle $(5 \times 5$ models $)$ with stimulation of one cell only (cell Al; first cell of the A-chain). $A: R_{g j}=\infty$ (0 channels). $R_{o l 2}=200 \mathrm{~K} \Omega$. Standard conditions. All 25 cells responded. $\mathbf{B}: R_{\mathrm{gi}}=1.0 \mathrm{M} \Omega$ (I0,000 channels). $R_{\mathrm{ol} 2}$ kept unchanged. The last 2 chains $(D, E)$ failed to respond. All 5 cells of each chain that responded $(A, B, C)$ fired simultaneously because of the strong cell coupling. $C:$ With $R_{g j}$ held at $I .0 M \Omega$, raising $R_{o l 2}$ to $10 M \Omega$ (representing tighter packing of the parallel chains) now allowed all 5 chains to respond. Thus, adding gj-channels inhibited transverse propagation, but this inhibition could be overcome by raising $R_{\mathrm{ol} 2}$. 
Table I: Summary of simulation data on cardiac muscle with stimulation either of single cell or entire chain.

\begin{tabular}{|c|c|c|c|c|c|c|}
\hline $\mathrm{R}_{\mathrm{gj}}(\mathrm{M} \Omega)$ & $\mathrm{R}_{\mathrm{ol} 2}(M \Omega)$ & $\mathrm{TPT}_{5 \mathrm{c}}(\mathrm{ms})$ & $\mathrm{TPT}_{4 \mathrm{c}}(\mathrm{ms})$ & $\mathrm{TPT}_{3 \mathrm{c}}(\mathrm{ms})$ & $\mathrm{TPT}_{2 \mathrm{G}}(\mathrm{ms})$ & $\begin{array}{l}\text { \# of chains } \\
\text { responding }\end{array}$ \\
\hline$\infty$ & 0.2 & 4.2 & 3.5 & 2.7 & & 5 \\
\hline 100 & 0.2 & 2.4 & 2.3 & 2.2 & & 5 \\
\hline 10 & 0.2 & --- & ---- & 2.1 & & 3 \\
\hline 1.0 & 0.2 & ---- & ---- & 2.1 & & 3 \\
\hline$\infty$ & 1.0 & 3.8 & 3.2 & 2.6 & & 5 \\
\hline 100 & 1.0 & 3.6 & 3.1 & 1.9 & & 5 \\
\hline 10 & 1.0 & ---- & ---- & 1.6 & & 3 \\
\hline 1.0 & 1.0 & ---- & ---- & 1.5 & & 3 \\
\hline$\infty$ & 5.0 & 2.7 & 2.6 & 2.3 & & 5 \\
\hline 100 & 5.0 & 2.0 & 1.6 & 1.2 & & 5 \\
\hline 10 & 5.0 & --- & ---- & 1.0 & & 3 \\
\hline 1.0 & 5.0 & ---- & ---- & 0.9 & & 3 \\
\hline$\infty$ & 10 & 2.4 & 2.2 & 2.0 & & 5 \\
\hline 100 & 10 & 1.5 & 1.3 & 1.0 & & 5 \\
\hline 10 & 10 & 2.6 & 1.2 & 0.8 & & 5 \\
\hline 1.0 & 10 & 2.9 & 1.3 & 0.8 & & 5 \\
\hline$\infty$ & 0.2 & 3.6 & 2.7 & 2.0 & 1.2 & 5 \\
\hline 100 & 0.2 & 2.5 & 2.4 & 2.4 & 1.2 & 5 \\
\hline 10 & 0.2 & ---- & ---- & ---- & I.I & 2 \\
\hline 1.0 & 0.2 & --- & ---- & --- & I.I & 2 \\
\hline$\infty$ & 1.0 & 2.6 & 2.1 & 1.5 & 0.9 & 5 \\
\hline 100 & 1.0 & 2.7 & 2.6 & 1.6 & 0.8 & 5 \\
\hline 10 & 1.0 & --- & ---- & 1.6 & 0.8 & 3 \\
\hline 1.0 & 1.0 & ---- & ---- & 1.6 & 0.7 & 3 \\
\hline$\infty$ & 5.0 & 1.7 & 1.4 & 0.9 & 0.6 & 5 \\
\hline 100 & 5.0 & 1.6 & I.4 & 0.9 & 0.6 & 5 \\
\hline 10 & 5.0 & ---- & 1.3 & 0.8 & 0.5 & 4 \\
\hline 1.0 & 5.0 & ---- & 1.3 & 0.8 & 0.5 & 4 \\
\hline$\infty$ & 10 & I.4 & I.I & 0.8 & 0.6 & 5 \\
\hline 100 & 10 & 1.3 & 1.0 & 0.8 & 0.5 & 5 \\
\hline 10 & 10 & 1.2 & 0.9 & 0.7 & 0.4 & 5 \\
\hline 1.0 & 10 & 1.2 & 0.9 & 0.7 & 0.4 & 5 \\
\hline
\end{tabular}

inhibited by insertion of gi-channels, up through the last chain activated (C-chain in case of Fig. 3 and B-chain in Fig. 4). If anything, the transverse velocity was increased slightly (TPT lowered). The TPT values (for differing amount of transverse spread of excitation, e.g. 2-chains, 3chains, 4-chains, or all 5-chains) are listed in Table 1 for different degrees of cell coupling. Note that, in part A, the largest change in TPT value is between $\mathrm{R}_{\mathrm{gj}}$ of $\infty$ ( 0 channels) and $\mathrm{R}_{\mathrm{gj}}$ of $100 \mathrm{M} \Omega$ (100 channels); adding more channels (Rgj of $10 \mathrm{M} \Omega$ (1000 channels) or $1.0 \mathrm{M} \Omega$
(10,000 channels)) did not further decrease TPT. Similar results were found when the entire A-chain was simulated (part B of Table 1).

The reader should be alerted to the limitations of the PSpice program. It was not possible to insert a second or third "black-box" in the basic excitable units (because the system went berserk). Therefore, the dynamic behavior of the cardiac cell membrane was only a close approximation. 

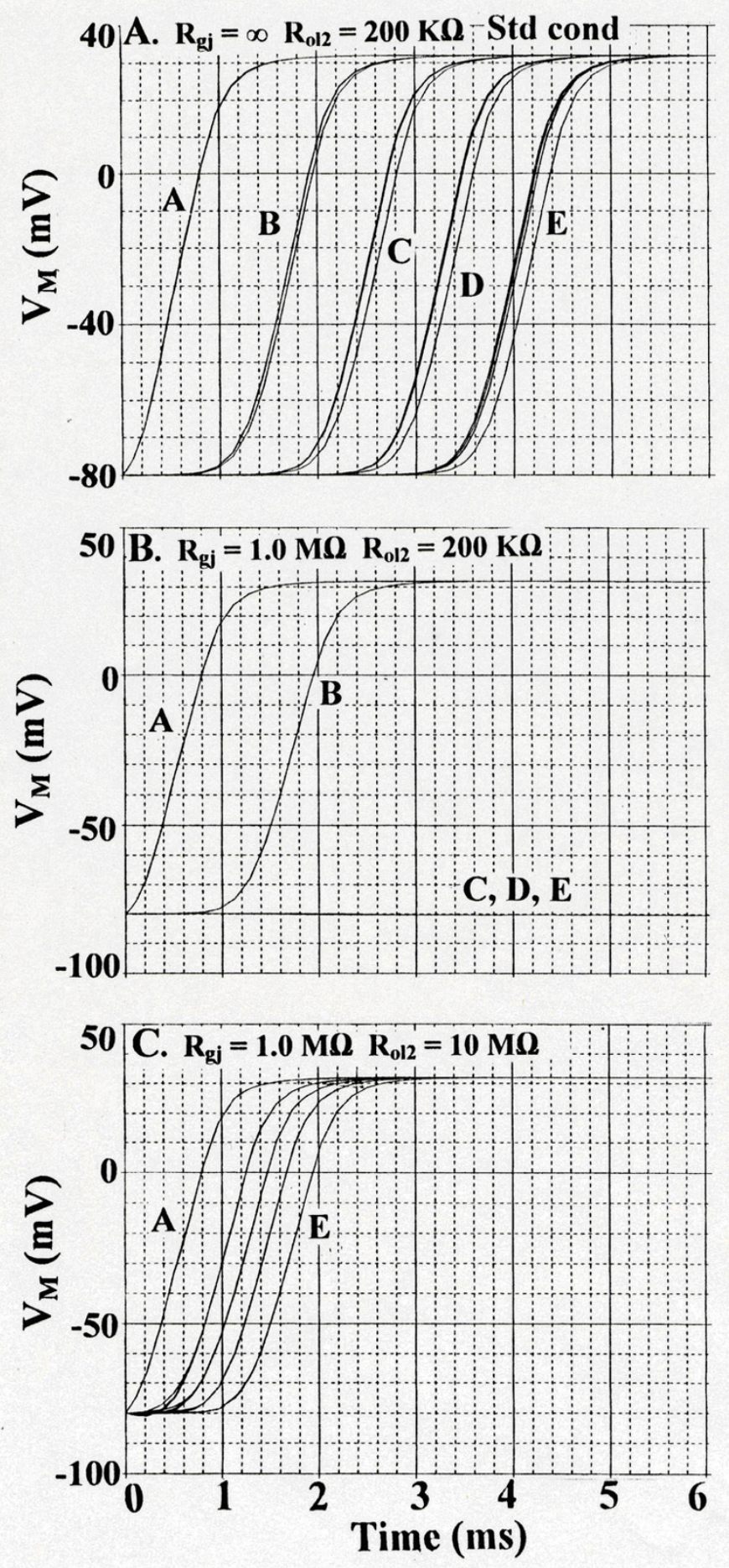

\section{Figure 4}

Transverse propagation of simulated APs for cardiac muscle with stimulation simultaneously of the entire A-chain. This was done as a better assessment of transverse propagation for comparison with stimulation of only one cell of the $A$-chain. $A$ : $R_{g j}=$ $\infty$ (0 channels). $R_{o l 2}=200 \mathrm{~K} \Omega$. Standard conditions. All 5 chains responded. $B: R_{g j}=1.0 \mathrm{M} \Omega(10,000$ channels $)$. With $R_{\text {ol2 }}$ kept at $200 \mathrm{~K} \Omega$, chains $\mathrm{C}$, D, and $\mathrm{E}$ failed to respond. $\mathbf{C}$ : With $\mathrm{R}_{\mathrm{gj}}$ held at $1.0 \mathrm{M} \Omega$, raising $\mathrm{R}_{\mathrm{ol} 2}$ to $10 \mathrm{M} \Omega$ (representing tighter packing of the chains) now allowed all 5 chains to respond. All 5 cells of each chain responded simultaneously because of the strong coupling. Thus, adding gj-channels inhibited transverse propagation, but this inhibition was overcome by raising $R_{\mathrm{ol} 2}$. 

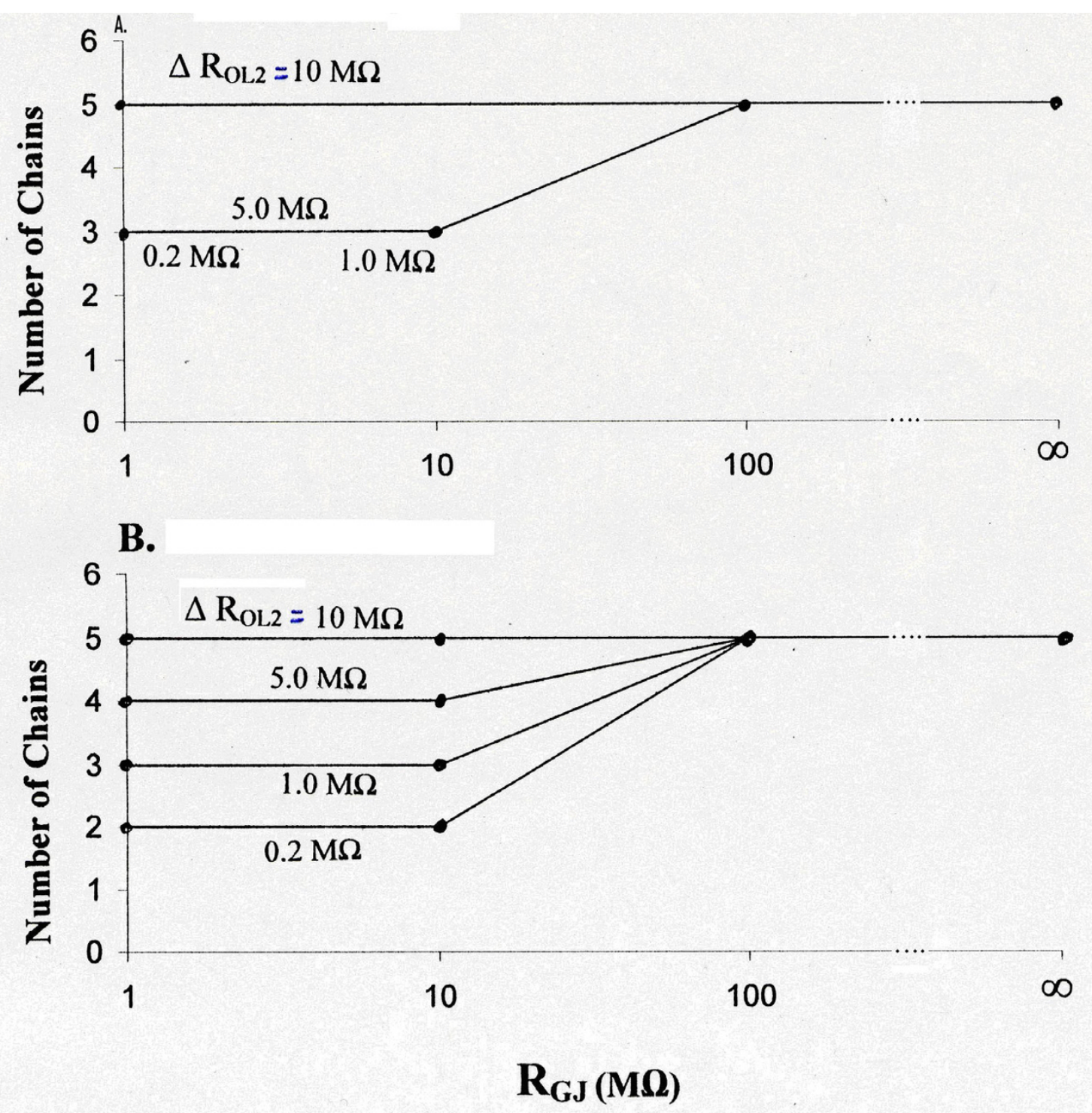

Figure 5

Summary of the transverse propagation experiments. Graphic plot of the number of chains responding as a function of $R_{\mathrm{g} j}$ for cardiac muscle, with stimulation of only one cell (cell AI) (panel A) or with stimulation of the entire A-chain (panel B). Data for various $R_{\mathrm{ol} 2}$ values $(0.2,1.0,5.0$, and $10 \mathrm{M} \Omega)$ are indicated. Four different $R_{\mathrm{gj}}$ values were tested: $\infty(0$ channels), $100 \mathrm{M} \Omega$ (I00 channels), I0 M $\Omega$ (I,000 channels), and I.0 M $\Omega$ (I0,000 channels). Thus, transverse propagation was depressed when there were many gj-channels ( 1000 or 10,000$)$, but elevation of $R_{\mathrm{ol} 2}$ could overcome this depression.

We previously found (unpublished observation) that the transverse velocity was greater when size of the model was increased (eg, $3 \times 4,5 \times 5,7 \times 7)$ up to a presumed maximum, indicating that the boundary conditions affected behavior of the model. Therefore, the present experiments should be repeated on larger-sized models. But we believe that the qualitative findings would be much the same. In addition, 2-dimensional activation maps should be made in the future to better elucidate how the wavefront spreads.

These findings might have important clinical implications, especially for the genesis of arrhythmias in pathophysiological situations. Any pathology that altered the 

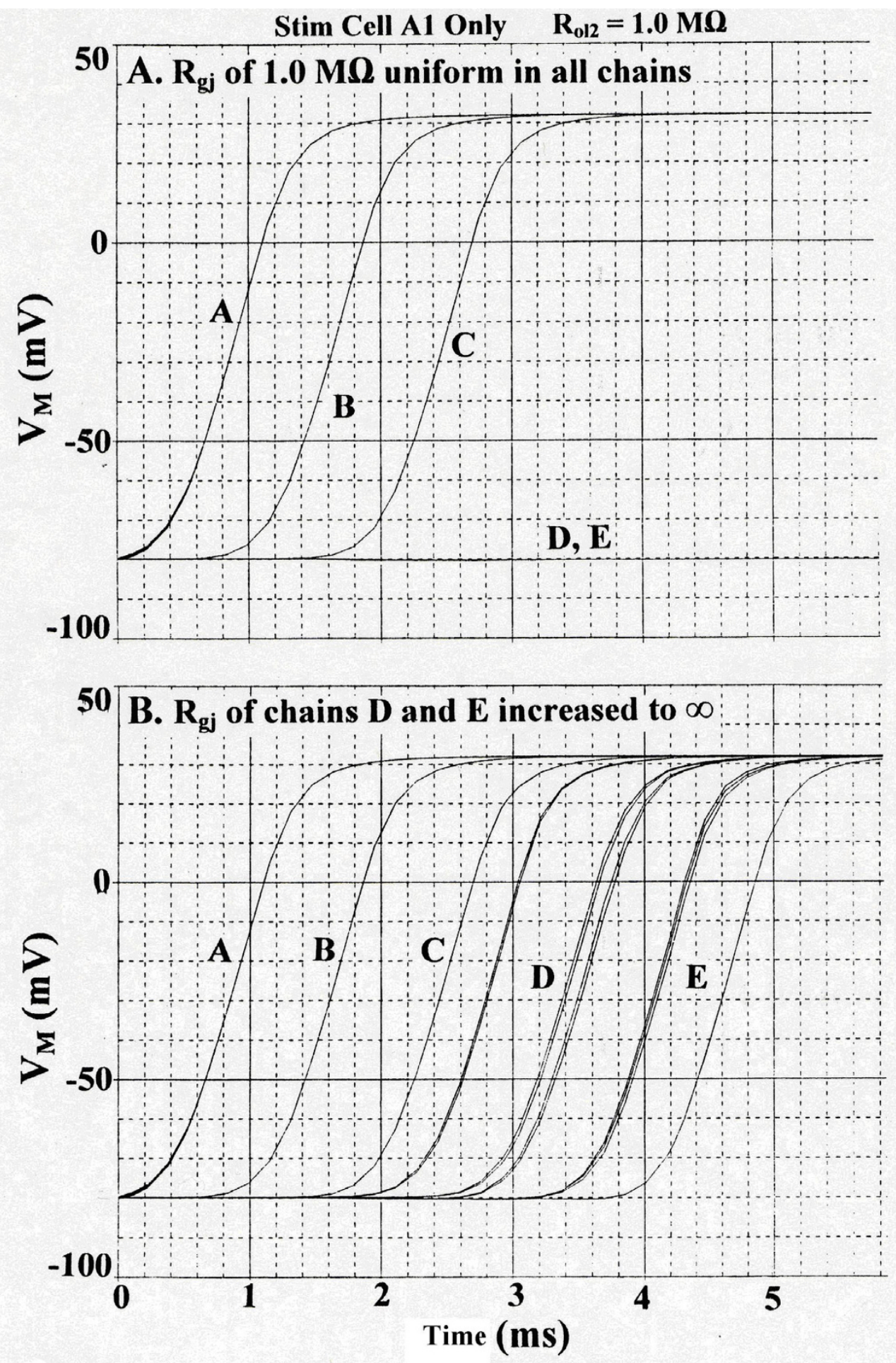

\section{Figure 6}

Special experiment to test why presence of many gap-junction channels inhibits transverse propagation. Stimulated Cell Al only. $R_{o 12}$ of I.0 M $\Omega$. A: Uniform value for $R_{g i}$ of $I .0 \mathrm{M} \Omega(10,000$ channels) in all 5 chains. Chains $D$ and $E$ failed to respond. Compare with Fig. $3 B$ for the standard $R_{\mathrm{ol} 2}$ of $0.2 \mathrm{M} \Omega$. B: The $R_{\mathrm{gj}}$ values in chains $\mathrm{D}$ and $\mathrm{E}$ only were changed to infinity $(0$ channels). Now chains $D$ and $E$ responded. See text for details. This demonstrates that removing the gj-channels in the two chains awaiting excitation $(D, E)$ increased the safety factor for transverse propagation. 
number of functioning gj-channels, not only would affect longitudinal velocity of propagation, but also the transverse propagation ability and velocity. Therefore, the genesis of some arrhythmias, e.g., the reentrant type, could be promoted under such conditions.

\section{Acknowledgements}

The authors thank Cara Stevens for typing the manuscript. The author also thanks Bijoy Kalloor, a graduate student in the Department of Electrical Engineering and Computer Science, assisted with the PSpice Program.

\section{References}

I. Sperelakis N, Mann JE Jr: Evaluation of electric field changes in the cleft between excitable cells. J Theor Biol 1977, 64:7I-96.

2. Picone JB, Sperelakis N, Mann JE Jr: Expanded model of the electric field Hypothesis for propagation in cardiac muscle. Math and computer modeling 1991, I5:17-35.

3. Sperelakis N, McConnell K: An electric field mechanism for transmission of excitation from cell to cell in cardiac muscle and smooth muscles. In Research Advances in Biomedical Engineering Volume 2. Edited by: Mohan RM. Global Research Network; 200I:39-66.

4. Sperelakis N, McConnell K: Electric field interactions between closely-abutting excitable cells. IEEE Eng Med Biol Mag 2002, 21:77-89.

5. Pertsov $A M$, Medvinski $A B$ : Electric coupling in cells without highly permeable cell contacts. Biofizika 1976, 2 1:698-700.

6. Hogues H, Leon LJ, Roberge FA: A model for study of electric field interactions between cardiac myocytes. IEEE Trans BiomedEng 1992, 30: 1232-1243.

7. Suenson M: Emphatic impulse transmission between ventricular myocardial cells in vitro. Acta Physiol Scand 1 992, I 20:445-455.

8. Barr RC, Plonsey R: Electrophysiological interaction through the interstitial space between adjacent unmyelinated parallel fibers. Biophys ] 1992, 6 I: I I64-I I75.

9. Spach MS, Miller WT, Geselowitz DB, Barr R, Kootsey JM, Johnson EA: The discontinuous nature of propagation in normal canine cardiac muscle. Evidence for recurrent discontinuity of intracellular resistance that affects the membrane currents. 198I, 48:39-54.

10. Diaz PJ, Rudy Y, Plonsey R: Intercalated discs as a cause for discontinuous propagation in cardiac muscle: A theoretical simulation. Ann Biomed Eng 1983, I I: 177-189.

11. Shaw RM, Rudy Y: Ionic mechanisms of propagation in cardiac tissue. Roles of the sodium and L-type calcium currents during reduced excitability and decreased gap junction coupling. Circ Res 1997, 8I:727-74I.

12. Henriquez AP, Vogel R, Muller-Borer BJ, Henriquez CS, Weingart R, Cascio WE: Influence of dynamic gap junction resistance on impulse propagation in ventricular myocardium: a computer simulation study. Biophys J 200I, 8I:2II2-2I2I.

13. Kucera JP, Rohr S, Rudy Y: Localization of sodium channels in intercalated disks modulates cardiac conduction. Circ Res 2002, 91 : I I76-1 I82.

14. Cohen SA: Immunocytochemical localization of $\mathrm{rHI}$ sodium channel in adult rat heart atria and ventricle. Presence in terminal intercalated disks. Circulation 1996, 94:3083-3086.

15. Sperelakis N, Editorial: An electric field mechanism for transmission of excitation between myocardial cells. Circ Res 2002, 91:985-987.

16. Morley GE, Vaidya D, Samie FH, Lo CW, Taffet SM, Delmar M, Jalife $\mathrm{J}$ : Characterizationofconductionintheventriclesofnormalandheterozygous Cx43 knockout mice using optical mapping. J Cardiovasc Electrophysiol 1999, I0:1361-1375.

17. Tamaddon HS, Vaidya D, Simon AM, Paul DL, Jalife J, Morley GE: High resolution optical mapping of the right bundle branch in connexin40 knockout mice reveals low conduction in the specialized conduction system. Circ Res 2000, 87:929-936.

18. Gutstein DE, Morley GE, Tamaddon H, Vaidya D, Schneider MD, Chen J, Chien KR, Stuhlmann H, Fishman Gl: Conduction slowing and sudden arrythmic death in mice with cardiac restricted inactivation of connexin43. Circ Res 2001, 88:333-339.
19. Vaidya D, Tamaddon HS, Lo CW, Taffet SM, Delmar M, Morley GE: Nullmutation of connexin 43 causes slow propagation of ventricular activation in the late stages of mouse embryonic development. Circ Res 200 I, 88: I I96-I 202.

20. Sperelakis N: Propagation of action potentials between parallel chains of cardiac muscle cells in PSpice simulation. Can J Physiol Pharmacol 2003, 8I:I-II.

21. Darrow BJ, Fast VG, Kleber AG, Beyer EC, Saffitz JE: Functional and structural assessment of intercellular communication. Increased conduction velocity and enhanced connexin expression in dibutyryl cAMP-treated cultured cardiac myocytes. Circ Res 1996: 174-183.

22. Sperelakis N, Ramasamy L: Propagation in cardiac muscle and smooth muscle based on electric field transmission at cell junctions: An analysis by PSpice. IEEE Eng Med Biol Mag 2002, 21:130-143

23. Sperelakis N, Murali KPV: Combined electric field and gap junctions on propagation of action potentials in cardiac muscle and smooth muscle in PSpice simulation. J Electrocardiol 2003, 36(4):279-293.

24. Sperelakis N, Kalloor B: Transverse propagation of action potentials between parallel chains of cardiac muscle and smooth muscle cells in PSpice simulation. Biomed Eng Online 2004, 3(1):5.

25. Thomas SP, Kucera JP, Bircher-Lehmann L, Rudy Y, Saffitz JE, Kleber AG: Impulse propagation in synthetic strands of neonatal cardiac myocytes with genetically reduced levels of connexin43. Circ Res 2003:1209-12 I6.

26. Hoffman BF, Cranefield PF: Electrophysiology of the Heart. McGraw-Hill Publishers; 1960.
Publish with Bio Med Central and every scientist can read your work free of charge

"BioMed Central will be the most significant development for disseminating the results of biomedical research in our lifetime. "

Sir Paul Nurse, Cancer Research UK

Your research papers will be:

- available free of charge to the entire biomedical community

- peer reviewed and published immediately upon acceptance

- cited in PubMed and archived on PubMed Central

- yours - you keep the copyright
BiolMedcentral 